\title{
Reacción adversa a la nadroparina cálcica intravenosa en hemodiálisis
}

\section{Amelia Martín Lorenzo - Cristina Bartolomé Rapado -Arsenio Tamerón Nieto}

\section{Unidad de Hemodiálisis. Hospital Virgen de la Concha. Zamora}

\section{Introducción}

Se conoce como alergia a la capacidad que posee una sustancia de provocar, tras su administración repetida, una reacción adversa por un trastorno de la inmunidad. Se manifiesta clínicamente por un conjunto de fenómenos respiratorios, cutáneos y cardiocirculatorios que pueden incluso provocar un shock anafiláctico.

Las alergias más frecuentes en hemodiálisis son las debidas al óxido de etileno, sustancia que se emplea en la esterilización de líneas, dializadores, etc. En la actualidad, es cada vez menos frecuente la aparición de estas reacciones de hipersensibilidad, bien sea a fármacos u otras sustancias, debido a que las técnicas se han perfeccionado y los materiales usados son más biocompatibles. No obstante, seguimos siendo sorprendidos por cuadros de este tipo, que, en ocasiones, nos ponen a prueba, ya que se trata de alergenos nuevos.

Desde el momento en que se sospecha una reacción alérgica, la enfermera tiene que actuar con la mayor prontitud, una vez tratado y fuera de peligro el paciente, se deberá profundizar en el diagnóstico, buscando los posibles desencadenantes. Solo el diagnóstico causal librará definitivamente al paciente del problema. A este diagnóstico, generalmente, se

\begin{tabular}{|c|}
\hline Correspondencia: \\
Amelia Martín Lorenzo \\
Unidad de Hemodiálisis \\
Hospital Virgen de la Concha \\
Avda. de Requejo, 35 \\
49022 Zamora \\
\hline
\end{tabular}

llega a través de la anamnesis, siendo especialmente relevante el registro de enfermería, donde queda reflejado de forma pormenorizada la descripción signos-síntomas, experimentados por el paciente, ya que, es la enfermera la que permanece junto al paciente durante todo el tiempo en que este recibe el tratamiento de hemodiálisis.

Para la anticoagulación en hemodiálisis puede utilizarse heparina de bajo peso molecular (HBPM) que se obtiene mediante la separación de una fracción de la heparina del resto de la molécula, esta fracción de heparina permite mantener la acción antitrombótica con menor efecto hemorrágico; si a esto le sumamos que produce menos reacciones alérgicas, es fácil comprender por qué su uso es cada vez más frecuente.

Describimos la reacción que experimentó uno de nuestros pacientes, sin alergias conocidas, a la heparina de bajo peso molecular (HBPM) nadroparina cálcica, durante el tratamiento dialítico. En nuestra unidad se utilizan las HBPM desde el año 1990 y la nadroparina cálcica desde el año 1996, en estos diez años de experiencia no hemos encontrado ningún otro caso de reacción alérgica a esta sustancia; tampoco hemos encontrada bibliografía alguna que describiera esta reacción.

Las HBPM se obtienen mediante la separación de una fracción de la heparina del resto de la molécula, esta fracción de heparina permite mantener la acción antitrombótica con menor efecto hemorrágico; si a esto le sumamos que produce menos reacciones alérgicas, es fácil comprender por qué su uso es cada vez más frecuente. 


\section{Objetivo}

Nuestro objetivo al presentar este caso, es ayudar a identificar lo más rápida y fácilmente posible reacciones de este tipo que hasta ahora no han sido descritas, difundiendo esta información entre los profesionales.

\section{Material y método}

Este estudio descriptivo y experimental, se llevó a cabo durante un mes; del (08-11-05 hasta el 08-1205), analizándose un total de diecisiete sesiones de hemodiálisis, realizadas a un único paciente, varón de 65 años intervenido de nefrectomía bilateral y por tanto con absoluta dependencia de hemodiálisis, que presentó un cuadro sintomático compatible con una reacción alérgica en varias ocasiones. Los parámetros estudiados fueron todas aquellas sustancias que entraron en contacto con dicho paciente durante la hemodiálisis:

- Tipo de dializador (más o menos biocompatible según el material del que está fabricado).

- Bicarbonatos y ácidos utilizados para elaborar el líquido de diálisis.

- Sustancias empleadas en la esterilización de dializadores, líneas, etc. (el óxido de etileno es el que ha producido más reacciones alérgicas).

- Suero heparinizado para purgar y lavar el circuito extracorpóreo.

- Heparina utilizada para la anticoagulación del paciente.

- Medicación que tomaba el paciente ya que, como sabemos, el tratamiento con inhibidores de enzimas de conversión de la angiotensina (IECAs) puede producir reacciones anafilácticas si se someten a hemodiálisis con membranas de alta permeabilidad.

Para poder evaluar los resultados, se revisaron minuciosamente todos los elementos y se fueron elaborando diferentes pautas de hemodiálisis, en las que se variaba alguno de estos parámetros hasta que se identificó el posible alérgeno.

\section{Resultados y discusión}

En la tabla 1 vemos la pauta de hemodiálisis a la que se sometió al paciente el primer día, la sesión transcurrió sin incidencias significativas. En el segundo día de diálisis se añade a este tratamiento nadroparina cálcica 0,3 iv como anticoagulante, no produciéndose ninguna reacción.

\begin{tabular}{|c|c|c|c|}
\hline \multicolumn{2}{|c|}{$\begin{array}{l}\text { HEMODIÁLISIS } \\
\text { SESIONES }\end{array}$} & $\begin{array}{l}\text { PRIMERA } \\
\text { PAUTA }\end{array}$ & $\begin{array}{l}\text { REACCION } \\
\text { ALÉRGICA }\end{array}$ \\
\hline \multirow[t]{7}{*}{ PRIMERA } & MONITOR & Multimat & \multirow[t]{7}{*}{ NO } \\
\hline & DIALIZADOR & F-80 (HELIXONA) & \\
\hline & $\begin{array}{l}\text { LÍQUIDOS DE } \\
\text { DIÁLISIS }\end{array}$ & BHD3 Al+ Bidry & \\
\hline & ESTERILIZACIÓN & Líneas óxido de etileno & \\
\hline & & Dializador con vapor & \\
\hline & LAVADO Y PURGADO & Prontoprime (1-litro) & \\
\hline & HEPARINIZACIÓN & No se realiza & \\
\hline
\end{tabular}

Tabla 1. Primera sesión de diálisis a la que se sometió al paciente.

En la tercera, cuarta y quinta sesión de diálisis se siguió la misma pauta, no produciéndose ninguna reacción, hasta la quinta sesión, en la que a los pocos minutos de haber conectado al paciente, presentó una reacción alérgica grave (calor, rubor, sudoración profusa y dificultad respiratoria).

Se revisó todo el material utilizado y se pensó que el causante era el óxido de etileno con el que estaban esterilizadas las líneas; ya que ni el material del que estaba compuesto el dializador (helixona), ni la forma de esterilización de este (con vapor), ni la medicación que el paciente tomaba sugirieron otra hipótesis.

Se elaboró otra pauta de tratamiento dialítico exenta de óxido de etileno en las líneas y se aumentó el suero de purgado a 2 litros. Durante la sexta sesión, no se produce reacción alguna, hecho que pareció confirmar nuestra hipótesis pero nuestras esperanzas de haber encontrado el alérgeno, duraron poco, ya que en la siguiente diálisis (la séptima), el paciente con esta misma pauta presentó un cuadro similar 
(calor, rubor, sudoración y dificultad respiratoria) lo cual podemos ver en la tabla 2. Se suspendió inmediatamente la hemodiálisis y se le administraron 100 mg. de actocortina; el paciente se recuperó en una media hora.

\begin{tabular}{|c|c|c|c|}
\hline \multicolumn{2}{|c|}{$\begin{array}{l}\text { HEMODIÁLISIS } \\
\text { SESIONES }\end{array}$} & $\begin{array}{l}\text { TERCERA } \\
\text { PAUTA }\end{array}$ & $\begin{array}{l}\text { REACCION } \\
\text { ALÉRGICA }\end{array}$ \\
\hline \multirow[t]{7}{*}{ SEXTA } & MONITOR & Integra & \multirow[t]{7}{*}{ NO } \\
\hline & DIALIZADOR & F-80 (HELIXONA)i & \\
\hline & $\begin{array}{l}\text { LIQUIDOS DE } \\
\text { DIALISIS }\end{array}$ & BHD3 Al+ Dial-Cart & \\
\hline & ESTERILIZACIÓN & Líneas con vapor & \\
\hline & & Dializador con vapor & \\
\hline & LAVADO Y PURGADO & Prontoprime (2-litros) & \\
\hline & HEPARINIZACION & Nadroparina Ca 0,3 & \\
\hline SEPTIMA & & & SI \\
\hline
\end{tabular}

Tabla 2. Se retira todo lo esterilizado con óxido de etileno.

Nuestra hipótesis se vino abajo; ante la necesidad de tener que dializar al paciente ese mismo día, hubo que elaborar otra pauta diferente introduciendo varios cambios. Nuestra prioridad fue evitar las sustancias utilizadas anteriormente (dializador, líquido de diálisis...) y prescindir de las que no fueran absolutamente necesarias (prontoprime, heparina...) con el único fin de simplificar al máximo la pauta de diálisis, y poder identificar mejor el alérgeno.

En la octava sesión, realizados los cambios y suprimida la heparinización (tabla 3), no se produjo ninguna reacción alérgica aunque se hace evidente la necesidad de anticoagular al paciente al que se le tuvo que interrumpir el tratamiento a las 2:30 h, por coagularse el circuito.

\begin{tabular}{|c|c|c|c|}
\hline \multicolumn{2}{|c|}{$\begin{array}{l}\text { HEMODIÁLISIS } \\
\text { SESIONES }\end{array}$} & $\begin{array}{l}\text { CUARTA } \\
\text { PAUTA }\end{array}$ & $\begin{array}{l}\text { REACCION } \\
\text { ALÉRGICA }\end{array}$ \\
\hline & DIALIZADOR & F-6 HPS (Polysulfona) & NO \\
\hline & $\begin{array}{l}\text { LIQUIDOS DE } \\
\text { DIALISIS }\end{array}$ & BHD3 A2+ Dial-Cart & \\
\hline & ESTERILIZACIÓN & Líneas con vapor & \\
\hline & & Dializador con vapor & \\
\hline & $\begin{array}{l}\text { LAVADO Y } \\
\text { PURGADO (1-litro) }\end{array}$ & Suero fisiológico & \\
\hline & HEPARINIZACION & No se realiza & \\
\hline
\end{tabular}

Tabla 3. Se suspende la heparina y se cambian componentes de la HD.
La siguiente sesión se plantea con la administración de nadroparina en 10 minutos y administrando la pauta de medicación recomendada por el equipo de alergólogos de nuestro hospital: consistía en tomar la noche anterior $6 \mathrm{mg}$. de Polaramine ${ }^{\circledR}$ más $32 \mathrm{mg}$. de Urbasón ${ }^{\circledast}$, repitiendo esta misma dosis dos veces, 3 y 1 horas antes de la hemodiálisis.

Nuestro paciente, ya premedicado, es conectado a la hora indicada por el servicio de alergología y vigilado atentamente por nuestro equipo. Transcurridos diez minutos desde el inicio de la hemodiálisis (consideramos el intervalo de los diez primeros minutos como de riesgo, ya que todas las reacciones se han producido en los tres primeros minutos), procedemos a la inyección de nadroparina a fin de anticoagular el circuito; apenas transcurrido un minuto el paciente comienza con una reacción similar a las anteriores. La pauta de medicación elaborada por el equipo de alergólogos no había conseguido su objetivo, pero al aparecer esta sintomatología inmediatamente después de la administración de nadroparina intravenosa, nos hizo sospechar que fuera esta sustancia la causante del problema. Esta teoría no era compartida por todos nosotros, puesto que el paciente estaba recibiendo tratamiento con nadroparina cálcica subcutánea los días entre diálisis, y no había presentado ninguna reacción alérgica ni local ni sistémica, aun así, se decidió utilizar una nueva pauta en la que la nadroparina se sustituyó por heparina sódica.

En la décima sesión el paciente no presentó ninguna reacción alérgica; en la undécima sesión, utilizamos la misma pauta pero suprimimos la premedicación antialérgica y obtuvimos buenos resultados. En las sucesivas diálisis, (doce, trece, catorce, etc.), se siguió la misma pauta y todas las sesiones han sido satisfactorias hasta el fin de 2006.

Llegado a este punto solo nos quedaba confirmar nuestra teoría mediante las pruebas de alergia, cuyos resultados fueron los siguientes:

- Pruebas cutáneas en prick é intradérmica con nadroparina negativas

- No se realiza prueba de tolerancia con nadroparina intravenosa, debido a que el paciente estaba tolerando la heparina sódica 


\section{CONCLUSIONES}

Por tanto pensamos que la causante del cuadro sintomático es la nadroparina cálcica administrada por vía intravenosa, ya que al suspenderla el paciente no ha vuelto a presentar hasta el momento actual ningún nuevo episodio. No podemos calificar esta reacción de alergia medicamentosa ya que las pruebas cutáneas son negativas y la administración vía subcutánea de iguales dosis de nadroparina no produjeron en el paciente reacción de ningún tipo (ni local ni sistémica); lo que indica que no hay trastorno de la inmunidad y lo que el paciente experimentó fue una reacción adversa a la nadroparina cálcica, es decir, un efecto farmacológico no deseado dosis-dependiente.

La importancia de estas conclusiones radica en lo inusual de este caso. Ya que las reacciones adversas son menos frecuentes en la HBPM que en las no fraccionadas y no hemos encontrado constancia bibliográfica de estas reacciones a la nadroparina por vía intravenosa.

\section{BIBLIOGRAFÍA}

1. Valderrábano F. Tratado de hemodiálisis. Barcelona. Médica JIMS. SL. 1999.
2. Vigarray Conde J, Cueto Baelo M. Guía de alergia para residentes de Atención Primaria. Ed. Díaz Santos S. 2001.

3. Cortado Macías JM, Torres Jaén JM, García Robaina JC, y Audicana $\mathrm{M}^{\mathrm{a}} \mathrm{T}$. Alergia a medicamentos. Sociedad Española de Alergología e Inmunología Clínica (S.E.A.I.C.). Sanidad Ediciones SL. Grupo Sanes 2005.

4. Ficha Técnica Fraxiparina; Nadroparina cálcica FT FXP 2 (14-12-04), Glaxo Smith Kline, S.A. Madrid.

5. Wütschert R, Piletta $P$, Bounameaux H. Adverse Skin Reactions to Low Molecular Weight Heparins. Frequency, Management and Preventión. Drug Safety; 1999.

6. Bekkenk M, Van Zuuren E. Inmediate type hypersensitivity after injectión of nadroparin (Fraxiparin). Thromb Haemost 2005; 94: 673-4.

7. Oieda E, Pérez MC, Matain R. Skin Necrosis With a Low Molecular Weight Heparin. British Journal of Haematology 1992; pag. 620.

8. Dacosta A, Mismetti P, Buchmuller A, Guy C. Hyperéosinophilie et lesions cutanées induites par héparine de bas poids moléculaire La Presse Médicale $1994 ; 23(3): 1540$. 